\title{
Views from the Front Lines: Observations by Chicago Lawyers About the System of Civil Discovery
}

\author{
Wayne D. Brazil
}

\section{Contents}

I. INTRODUCTION

II. CIVII Discovery

III. The SUbWorld of SMaller Cases

IV. The Subworld of LARger CASES

A. Dimensions of Inefficiency

B. Thoughts About Cases

2. The Untoward Role of the Judiciary 


$$
\text { * }
$$




\section{Views from the Front Lines: Observations by Chicago Lawyers About the System of Civil Discovery}

Wayne D. Brazil

This is the first in a series of articles that will report the results of a pilot effort to assess how well the system of civil discovery is working and to identify the principal problems which burden that system. The study revolves around interviews with 180 Chicago area litigators. This first essay, which synthesizes observations, insights, and complaints by interviewed attorneys, suggests that the world of civil discovery is not one monolithic whole, but consists of subworlds which exhibit clearly distinguishable features and problems. In addition to describing the principal problems which afflict the discovery system in its two major subworlds, the author reports what the interviewed lawyers suggest are the primary causes of those problems. While the litigators identify many ways in which the character of lawyering encumbers and disrupts the discovery process, they also locate much of the blame for the system's problems in the behavior of judges and the inefficiency of the judicial machinery. The interviews produced a dramatically widespread appeal to the courts to increase use of sanctions as a means of restraining discovery abuse.

\section{INTRODUCTION}

Growing national concern about the effectiveness and efficiency of pretrial discovery in civil litigation has prompted the American Bar Foundation to sponsor a pilot empirical exploration of practicing attorneys' experiences with discovery and perceptions of its problems. The core of the pilot project consisted of interviews of 180 Chicago area attorneys

Wayne D. Brazil is Associate Professor of Law, University of Missouri, Columbia; Affiliated Scholar, American Bar Foundation. B.A., 1966, Stanford University; M.A., 1967, Ph.D., 1975, Harvard University; J.D., 1975, University of California, Berkeley. Professor Brazil is the project director of the American Bar Foundation pilot study about which this essay reports. He would like to take this opportunity to express his appreciation to several people who contributed significantly to this project. As research associate, Janna Dee Bounds helped design the questionnaire and structure the sample group and, most important, conducted interviews of about 70 attorneys. Her perseverance and professionalism were crucial to the success of the entire undertaking. As research assistants, Jennifer Ballsrud and Kenneth Ashlock painstakingly transferred data from questionnaires to computer coding forms, organized qualitative responses, and digested computer printouts. Sheila Schneider and Roberta Painter performed numerous technical services very expeditiously. Clara Carson, Phyllis Satkus, and Betsy Reed helped draft coding instructions and wrote several programs for the computer analysis. Finally, Spencer Kimball, Barbara Curran, Louis Potter, and Jack Heinz made important contributions to the design of the study and to the structure and content of the questionnaire. 
which the project director and his research associate conducted during the summer of 1979. The lawyers interviewed were selected from virtually all the major components of the civil litigation community, and the resulting sample group was a well-balanced composite of attorneys from many different kinds of practices and sizes of firms. ${ }^{1}$

The questionnaire which structured the conversations with the selected attorneys was refined through more than 30 pretest interviews. That refining process resulted in a final version of the questionnaire ${ }^{2}$ (instrument) which was used in the remaining 144 interviews. The instrument was designed to yield (1) information about the nature of each respondent's practice and professional experience, (2) general, open-ended evaluations of the discovery system, (3) estimates of the principal problems with and abuses of discovery, (4) data about the extent to which certain kinds of obstacles impair discovery efforts, (5) information about the role tactical considerations play during the discovery stage and about how

1. The project director and a research associate interviewed 180 Chicago lawyers (yielding 177 completed questionnaires-in three interview sessions two attorneys participated simultaneously). The sample group that resulted will be described in detail in a forthcoming A.B.F. Research Journal article, which will report the quantitative data generated by the interviews. A few generalizations about the composition of the group, however, are in order here.

The interviewed attorneys represented a wide range of types of practices and a good mix of kinds of cases. Inputs from no one type of practice could dominate the data. Among the 180 attorneys, for example, 70 indicated that antitrust matters had been among the principal kinds of cases on which they had worked during the preceding five years, while 64 indicated that their practice had included miscellaneous (generally smaller case) tort matters. Forty-five had been involved in securities litigation, while 31 had handled personal injury cases arising out of automobile accidents.

The sample group was also well balanced with respect to the median dollar size of the cases on which the attorneys had worked. All were asked to estimate the median dollar value of the cases in which they had been involved over the preceding five years. The answers ranged from four to eight digits, the median being approximately $\$ 150,000$. The figures also show that the group was well balanced on the extremes: 39 attorneys indicated that the median value of their cases had been $\$ 25,000$ or less, while 42 lawyers reported $\$ 1,000,000$ or more.

In several other characteristics the sample group was nicely balanced. While the median size of the firms in which the interviewed attorneys practiced was 20 lawyers, 55 practiced in firms of 5 or fewer and 51 in firms of 70 or more. The median year of admission to practice for all 180 lawyers was 1965. Thirty-eight were admitted before 1955 (so had 25 or more years of experience), 44 after 1969 (so had less than 10 years of experience). The sample contained roughly comparable numbers of plaintiffs' and of defense lawyers. The median of the responses reflecting the percentage of time the lawyers spent on plaintiffs' and on defendants' matters suggests that the aggregate commitment from the group to the two different types of clients was evenly balanced. More respondents, however, devoted three-fourths or more of their time to defendants' matters (62 attorneys) than devoted that much of their time to plaintiffs' matters (47 attorneys). Finally, the median of the figures reflecting the relative percentage of time the lawyers in the group committed to matters filed in state court and to matters filed in federal court indicates that the aggregate involvement was evenly divided between the two court systems. At the extremes, however, the sample was weighted slightly in favor of attorneys who practiced primarily in the state courts. While 62 respondents indicated that they committed 79 percent or more of their time to matters filed in federal court, 76 committed that percentage or more of their time to state court matters.

2. The final version of the questionnaire will be reproduced in an appendix to an article in a subsequent issue of the Research Journal. In the interim, copies of the questionnaire can be obtained from the author, who may be contacted for this purpose through the American Bar Foundation. 
often discovery tools are used for specific tactical purposes, (6) assessments of how successfully other attorneys use discovery techniques, (7) insights into the roles clients play in generating resistance to discovery, (8) recommendations for improvements of the current system, and finally, (9) indications about how the interviewed lawyers would react to possible changes in the scope of discovery and in the pretrial role of the courts.

The data the interviews produced are divisible into two broad categories: (1) quantifiable responses that evidence the perceived dimensions and frequency of certain phenomena in the world of discovery and (2) qualitative evaluations of the discovery system, perceptions about some of its dynamics, and thoughts about the causes of some of its most prominent characteristics. The purpose of this essay is to report, in an integrated format, the information produced by the interviews that falls into the second ("qualitative") category. The study's quantifiable results will be reported in a subsequent issue of the Research Journal.

Before proceeding it is appropriate to offer a few observations about the value and the limitations that attach to the information this study has produced. What we report are perceptions, attitudes, and ideas of some 180 Chicago litigators. These responses cannot "prove" anything, even about the 180 lawyers who provided them. Nor is it clear to what extent the responses might parallel responses that would be offered by other Chicago attorneys, by civil litigators in other major metropolitan areas, or by lawyers in smaller towns or rural areas. Nonetheless, these reported perceptions, attitudes, and ideas not only constitute evidence about what is "really" happening in parts of the world of civil discovery but also probably help shape that "reality" by affecting the way these litigators practice.

The pages that follow reflect an effort to synthesize and shape hundreds of observations and insights into coherent pictures of some of the principal characteristics of the discovery system. The process of synthesizing, generalizing, and integrating data into such pictures inevitably does some disservice to the complexity of reality. It creates images whose clarity masks tensions and inconsistencies. It is important to recognize that there are many such tensions and inconsistencies within both the qualitative and quantitative data produced by this study. For virtually every generalization there appear to be exceptions; from virtually every opinion there appear to be dissents; for virtually every perception there appear to be contradictions. Attorneys who seemed to be very similarly situated sometimes offered wide ranges of responses to the same questions, suggesting that even attorneys whose practices seemed almost identical sometimes have had different experiences with at least some aspects 
of the discovery process. While such variations and tensions within the data are:not so great as to make generalization impossible (some patterns in the data are so clear that they compel recognition), their presence should serve as a pointed reminder to proceed cautiously with the process of interpretation and as evidence of the need for additional, larger scale, and more refined studies.

\section{Civil Discovery: A Divisible World}

One of the most important and dramatic generalizations supported by both the qualitative and quantitative data is that the world of discovery is so far from being monolithic that it makes little sense to conceive of it or to treat it as if it were one integrated whole. Instead, the world of civil discovery appears to be composed of subworlds, domains with boundaries that are not sharp but that seem to be determined primarily by factors such as the size and complexity of the cases in which the discovery takes place and the nature of the clients being served. ${ }^{3}$ The data generated by this pilot project are not sufficient to support an effort to determine how many such subworlds might exist or to plot their probably overlapping borders. ${ }^{4}$ The data strongly support the hypothesis, however, that the world of civil discovery contains at least two clearly identifiable, major subworlds between which there are significant differences. The characteristic inhabitants of one of these subworlds are small (in dollar value), relatively simple, relatively routinized cases, typified by (but by no means limited to) personal injury lawsuits arising out of automobile accidents. The characteristic inhabitants of the other subworld are large (in dollar value), complex (both in terms of legal theories and the volume of information that needs to be digested), thoroughly developed cases, typified by (but by no means limited to) antitrust litigation. ${ }^{5}$ The data

3. The data to support this proposition will be presented systematically in a subsequent issue of the Research Journal.

4. In addition to the two major subworlds discussed in the text, interviewed attorneys suggested that relatively discrete discovery subworlds might exist in such areas as family law, admiralty cases, and patent, trademark, and copyright litigation.

5. Presumably there are many cases whose traits do not perfectly match those of the "characteristic" types that dominate each subworld. Despite differences in some features, however, many such cases probably have enough in common with the characteristic cases in one of the subworlds to fit relatively comfortably. Other cases, however, may not fit easily.

Professors John P. Heinz and Edward O. Laumann are conducting, under the sponsorship of the American Bar Foundation, studies of the Chicago bar which appear to offer corroboration for this hypothesis of two dominant "subworlds." Data generated by Heinz and Laumann (through interviews of more than 750 Chicago lawyers) suggest that in many professionally, politically, and socially significant respects the bar is divided into two "hemispheres" and that the primary determinant of the border between the two is the nature of dominant client types. According to Heinz and Laumann, lawyers who primarily serve corporations inhabit one of these hemispheres and have relatively little in common with the lawyers who primarily serve individuals and small businesses that inhabit the other hemisphere. See John P. Heinz \& Edward O. Laumann, The Legal Profession: 
produced by the interviews, taken as a whole, indicate that the discovery process in each subworld tends to exhibit certain general characteristics ${ }^{6}$ and that it is with respect to some of these prominent characteristics that the contrast between the two major subworlds is most striking.

\section{The Subworld of Smaller Cases}

In the subworld of the smaller, simpler, more routinized cases discovery appears to play a less dominant role in the litigation process than it does in the subworld of large, complex lawsuits. ${ }^{7}$ While discovery's role is not unimportant in smaller case litigation, in this subworld counsel devote a lower percentage of their total billable time to discovery than do attorneys working in complex litigation. The small case lawyer commits higher percentages of his time than does his large case counterpart to investigations, negotiations, and trials. In the smaller cases, then, discovery tools are used less often and less intensively than in more complex matters.

Moreover, according to attorneys in the sample group the use of discovery tools seems to be more straightforward and less affected by tactical purposes in smaller cases than in larger cases. ${ }^{8}$ The discovery process also was reported to be less encumbered by friction, evasion, and harassment in the subworld composed of the smaller cases. ${ }^{9}$

The attorney-client privilege and other doctrinal protections of infor-

Client Interest, Professional Roles, and Social Hierarchies, 76 Mich. L. Rev, 1111 (1978), and Edward O. Laumann \& John P. Heinz, The Organization of Lawyers' Work: Size, Intensity, and CoPractice of the Fields of Law, 1979 A.B.F. Res. J. 217.

6. There are, of course, individual cases in each subworld that do not fit the pattern.

7. For purposes of comparing discovery characteristics, we have defined "smaller" case lawyers as those whose median-sized case, over the preceding five years, has involved a dollar value of $\$ 25,000$ or less and larger case lawyers as those whose median-sized case has involved $\$ 1,000,000$ or more. By "simpler" cases we mean those in which theories of liability are relatively straightforward (e.g., negligence) and which do not require analysis of vast quantities of data.

8. The full complement of quantifiable data that support these generalizations will be reported in a subsequent issue of the Research Journal. Here a few examples must suffice. Respondents in the sample group were asked if the purpose of imposing work burdens or economic pressure on another party or attorney ever had been a factor affecting their use of discovery tools. Thirty-five of 44 ( 85 percent) of the larger case attorneys (see note 7 supra) said yes; 30 of 39 smaller case attorneys (77 percent) also answered in the affirmative. The lawyers also were asked to approximate the percentage of their cases during the preceding five years in which the purpose of imposing work burdens or economic pressure had been a factor affecting their discovery. The mean of the percentages given by 30 smaller case lawyers was 18; that given by 34 larger case attorneys was 36 .

9. All 157 attorneys to whom the following question was posed answered it in the affirmative: "Have evasive or incomplete responses to your discovery requests ever made your discovery more difficult or accounted for your not discovering or pursuing some information?" The attorneys then were asked to estimate the percentage of their cases during the preceding five years in which evasive or incomplete responses had been sources of difficulty for their discovery efforts; the mean of the percentages offered by the 37 smaller case lawyers who responded was 47; the mean for the 38 larger case attorneys who responded was 72 . 
mation apparently play less visible roles in smaller case litigation than in its more complex counterpart; that is, privileges were reportedly sources of difficulty or obstacles to discovery substantially less often for predominantly smaller case lawyers than for lawyers who commit most of their time to larger matters. ${ }^{10}$ The full extent of the role the privileges play as obstacles to discovery, however, may not be visible. Information may often be concealed by the so-called "silent assertion" of a privilege-withholding information in response to discovery requests (e.g., document production demands or interrogatories) without informing the discovering party either that additional information exists or that the party responding to the discovery is claiming that the information is protected against disclosure by a privilege. Thus, unless on every discovery occasion the requesting party explicitly asks the responding party to indicate whether information is being withheld on grounds of privilege, he or she may well never learn that additional information exists and thus may never have an opportunity to challenge the applicability of the privilege to it. Because no direct question about "silent assertions" was built into the questionnaire for the pilot study, the data offer no indication about how widespread this practice might be. That it was reported and that concern about it was expressed, however, suggest the need for further exploration of its role. Because it appears that attorneys working on larger cases are less likely to fail to demand that other parties identify all data withheld on grounds of privilege, the problems created by "silent assertions" may be most significant in smaller cases. The existence of this phenomenon may support the need for some form of discovery compliance affidavits, a reform proposal suggested by interviewed attorneys that will be discussed in a subsequent article.

Interviewed attorneys suggested that some of the characteristics of smaller case discovery are attributable in part to the fact that the amounts in controversy in such litigation are too small to justify the higher costs (attorneys' fees) which tactical maneuvering would generate. Another explanation is the perception that in the simpler cases there is less room for tactical jockeying and less to be gained by it because the issues and evidence tend to be relatively straightforward and predictable. Because in smaller cases the issues tend to be easier to identify and the existence and sources of potentially relevant evidence tend to be more predictable, discovery reportedly functions better as a system for information distribu-

10. When asked if the attorney-client privilege ever had made their discovery more difficult or accounted for their failure to pursue or acquire information, only 19 of 37 (51 percent) smaller case lawyers said yes, whereas 32 of 38 ( 84 percent) larger case litigators said yes. The attorneys also were asked to estimate the percentage of their cases during the preceding five years in which the attorneyclient privilege had been an obstacle to their discovery; the mean of the percentages provided by the 19 smaller case attorneys was 22; for the 32 larger case respondents, 51 . 
tion in small than in large cases. Predominantly small case litigators are significantly less likely than their large case counterparts to settle or to try a case believing that they know something significant that another party has not discovered."

While in many important respects the discovery system appears to function better in small case litigation than it does in more complex lawsuits, the subworld of small case discovery is by no means free of significant problems. One such problem reported by litigators whose practices primarily involve smaller cases is vulnerability to economic pressure, pressure which opponents with more substantial resources can impose through discovery devices. While the data produced by the pilot project are not sufficient to support estimates about how often larger law firms or wealthier parties use expansive discovery demands to pressure or harass opponents with fewer resources, ${ }^{12}$ it is clear that fear of being subjected to such pressures is a real part of the professional life of many smaller case lawyers. Some of our respondents, for example, reported that they counted on their opponents' forgoing discovery opportunities or not using discovery tools that clearly were available. In a similar vein, some smaller case lawyers reported considerable frustration over the fact that the great cost of engaging in substantial discovery often prevented them from even making the effort. Some also reported that the projected expense of responding to and conducting discovery more than occasionally pressured them to advise a client to accept a settlement even though they knew the case was underdeveloped and even though they suspected that an opponent possessed relevant information that they had not yet discovered. ${ }^{13}$

Evasive or incomplete responses to discovery requests, while apparent-

11. While 77 percent of each group indicated that on one or more occasions they had tried a case to completion believing that they possessed arguably significant information which another party had not discovered, there is a major difference in frequency. Thirty-nine attorneys in each subgroup were asked to estimate the percentage of cases they had tried to completion during the past five years believing they still knew something arguably significant about the case that another party had not discovered. The mean of the percentages provided by the smaller case attorneys was only 16 , whereas that mean for the larger case attorneys was 41 .

12. The questionnaire did not include a question about how often "harassment" was a problem. The interviewers asked each respondent, however, to identify problems with or abuses of the system. Eleven of 39 (28 percent) smaller case attorneys volunteered that harrassment was such a problem. But the percentage of larger case attorneys who voluntarily identified harassment as a problem was substantially higher: 45 . Similarly, "overdiscovery" was voluntarily identified as a problem or abuse by 38 percent of the smaller case lawyers and by 62 percent of their larger case counterparts. Both problems may be a function of complexity of cases as well as of disparate resources.

13. Thirty-four smaller case lawyers were asked to estimate the percentage of the cases they had settled during the preceding five years in which they "suspected ... that another party had relevant information (including information legitimately protected by privilege or other rules) that [they] had not discovered." The mean percentage of the responses to this question provided by the smaller case lawyers was 31 . In contrast, the mean percentage of the responses to the same question by 41 larger case lawyers was 49 . The higher mean percentage in the latter case may reflect in part the complexity of the cases. 
ly less often a source of difficulty for small case lawyers than for their large case counterparts, nonetheless reportedly impede discovery in almost one out of every two smaller lawsuits. ${ }^{14}$ As significant a problem as evasion seems to be, however, smaller case litigators complained more frequently and vehemently about two other problems: difficulty in scheduling discovery events and delay. Scheduling problems reportedly plague and in some measure demoralize a large percentage of small case litigators in Chicago. ${ }^{15}$ One personal injury lawyer claimed (and had his secretary verify) that, on the average, each deposition in his cases is continued (rescheduled) between 15 and 20 times. Many lawyers pointed out that the constant rescheduling of discovery events not only is a source of considerable frustration and stress for both clients and attorneys but also substantially slows the dispute resolution process, decreases its efficiency, and increases its cost.

Those of our respondents who discussed the causes of this apparently severe scheduling problem tended to concur that while it is attributable in part to harassment and to efforts by counsel to gain tactical advantages, a perhaps more significant cause is the size of the caseloads which high volume, smaller case litigators seem to feel constrained to carry. According to this view, low profit margins and fear that the flow of new work into the office may not continue generate pressures on smaller case lawyers to overcommit themselves. Overcommitments, in turn, result in scheduling difficulties and conflicts. Moreover, once conflicts and continuances become patterned facts of life, litigators intensify the problem by assuming that many continuances will occur and, therefore, construct discovery schedules which incorporate many conflicts in advance. Several respondents also suggested that very large caseloads and overcommitted schedules might account for the fact that high volume, smaller case attorneys often seem unresponsive to discovery requests.

At least in some measure, scheduling difficulties also appear to be evidence of and caused by the larger and more serious problem of delay. The data produced by the pilot study suggest that in the Chicago area delay is perceived as the biggest single problem confronting the smaller case litigator in the discovery arena. ${ }^{16}$ As used by our respondents, the

14. See note 9 supra.

15. Because scheduling difficulties may be caused, at least in part, by the lengthy delays between the filing of a complaint and trial in the Illinois state courts in Cook County, the severity of the scheduling problems described in the text may be peculiar to jurisdictions in which trial docket backlogs impose lengthy waits (several years) for trial dates.

16. Fifty-four percent of the smaller case lawyers voluntarily identified delay as a problem in the discovery system. Moreover, smaller case attorneys indicated that extended delay was a problem in a higher percentage of their cases than were other major obstacles to discovery. Fifty-three percent was the mean of the percentages provided by 37 smaller case lawyers who were asked to estimate the percentage of their cases during the preceding five years in which extended delay had been a source of difficulty in their discovery. 
term "delay" refers to many related phenomena: procrastination in investigation and case development, tardy initiation of discovery, tardy responses to discovery requests, repeated continuances of discovery events, inexpeditious access to courts to hear discovery disputes, occasionally slow judicial responses to discovery problems, and, most important, distant trial dates.

Some of the interviewed attorneys said one cause of delay is intentional tactical jockeying by counsel. ${ }^{17}$ One attorney volunteered, in describing the factors he considered when plotting the sequence of his discovery, that when he wanted to "slow things down" he would make discovery demands that would provoke time-consuming disputes with his opponents. Another lawyer proudly recounted how, by manipulating the discovery process, he had "horsed around" opposing parties so as to create enough time for a financially troubled client to collect outstanding debts and thus avoid bankruptcy. Other lawyers admitted they would occasionally respond evasively to discovery requests primarily to "buy" time that their crowded schedules would otherwise not yield.

There appears to be a consensus among smaller case litigators, however, that distant trial dates, not tactical machinations, are the principal sources not only of the other dimensions of the delay problem but also of many other inefficiencies in small case litigation in the Chicago area. In the law division of the state courts in Cook County trial dates are indeed distant: interviewed litigators reported that, on the average, five years elapse between filing a civil complaint and bringing a matter to trial. ${ }^{18}$ Backlogs in the civil trial dockets in the federal district courts for the northern district of Illinois reportedly were substantially less severe; litigators estimated that in these federal courts the time between filing complaints and trial dates averaged about two years. In the federal system, however, the precedence given to criminal proceedings reportedly causes significant and unpredictable additional delays and interruptions.

Interviewed litigators suggested that substantial trial docket backlogs often begin vicious circles of procrastination which intensify the inefficiency of the discovery process. Among other things, the absence of pressing trial dates and the long periods between the initiation of lawsuits

17. Twenty-eight of 39 (72 percent) smaller case lawyers said the purpose of gaining time or slowing down an action had been a factor affecting their use of discovery on one or more occasions. They were asked to estimate the percentage of their cases during the preceding five years in which such a purpose had been a factor affecting their discovery; the mean of the percentages was 28 .

18. They reported that substantially earlier trial dates were available in the equity division and that the more pressing trial dates in that division generally had a salutary effect on the efficiency of discovery. When compelled by a rapidly approaching trial date to complete discovery expeditiously, counsel reportedly managed to do so. This suggests that in jurisdictions where early trial dates are available, many of the problems caused or exacerbated by the severe backlog in the law division's civil trial docket in Cook County might be substantially less severe. 
and their trials apparently reinforce the temptation smaller case lawyers in Chicago already feel to overcommit themselves, i.e., to accept responsibility for a larger number of cases than they can handle adequately and thus to set the stage for the scheduling problems described above. Knowing that a trial date is five years away also reportedly encourages some attorneys to postpone conducting investigations on the theory that the less detail they (and their clients) know about their side of a case the less they will have to disclose in response to discovery probes from other parties and the less of opposing counsel's work they will do. One litigator said that attorneys often postponed hiring an expert until just before the trial was scheduled to commence in the hope that the cost could be avoided and that discovery probes about the expert's work could be avoided as well. Similarly, foreseeing that a trial remains years in the future leads some litigators to postpone discovery on the theory that the earlier they submit their discovery requests the less they will learn from the opponent and the more likely they will have to follow up or repeat their early discovery efforts. Moreover, if permission from the court is required before counsel can re-explore subjects of past discovery probes, or if an opponent is likely to object to a second effort (even though much later) to pose questions in a given subject area, there is additional pressure to postpone discovery because early discovery may create a risk that counsel will be unable to acquire all the discoverable information an opponent ultimately might possess. One respondent suggested that postponing case development and discovery often results in counsel's not being adequately prepared for trial when its date finally arrives.

The several-year interval between initiating a lawsuit and bringing it to trial also tends to discourage defendants from attempting to reach prompt settlements. Attorneys in the sample group pointed out that clients who perceive an opportunity to postpone payment of a probable obligation for four or five years will often have strong incentives to do so. Instead of satisfying a claim promptly, such clients will often feel tempted to commit their funds to high yield investments for the several years before a judgment would compel them to pay the claimant. The foreseeability of the long hiatus before the obligation would become payable makes the opportunity cost of early settlement both painfully ob. vious and higher. The temptation to postpone settlement is reinforced by the impact of high rates of inflation on the value of settlement dollars. Defendants often believe that by delaying payment on a claim for several years they will be able to settle or satisfy a judgment with dollars cheapened by inflation. The temptation to postpone settlement that is created by the combination of opportunity cost and inflation often may 
be irresistible to a decision-maker who feels a duty to minimize losses and to maximize the rate of return on available resources. Thus, the net gain from alternative investments and high inflation rates may result in postponement of settlement, reducing substantially the total cost of satisfying some kinds of debts. Under some circumstances, of course, judgments may include prejudgment interest and/or adjustments to reflect the impact of inflation. To the extent that it is foreseeable that given judgments will include full compensation both for interest and inflation, litigants may perceive less, or no, incentive to postpone settlement.

Interviewed lawyers suggested one additional important respect in which the five-year wait for a trial date can create disincentives to settle cases early. Some defense counsel (and their clients) believe that the longer they can postpone resolution, the greater the odds become that their opponents will (1) not be able to marshal persuasive evidence to establish liability (some memories will fade and witnesses may become unavailable over a five-year period); (2) be pressured by changed financial circumstances or loss of psychological staying power to accept a smaller settlement; or (3) disappear altogether. In short, litigators are tempted to believe that a day of judgment five years away may never come. That belief deprives the fear of an adverse judgment of its power to inspire prompt action. Observations like these led several attorneys to suggest that the key to improving the efficiency of discovery in smaller case litigation is to equip the civil courts with the power and capacity to confront lawyers and clients with fixed and early trial dates. Some have suggested that giving courts such power also might discourage the filing of complaints before counsel have conducted sufficiently thorough investigations to be sure their clients have litigable cases.

\section{The Subworld of Larger Cases}

The second major subworld of civil discovery is inhabited by larger, more complex cases. While the phenomena which define the character of discovery in this subworld are not confined to it, they occur more frequently and appear in substantially more pronounced dimensions here than in the subworld of smaller, less complex cases. The data produced by the interviews suggest that as the kinds of cases under study become larger and more complex they generally (but obviously not without exception) tend to exhibit the following kinds of characteristics: (1) discovery consumes a very substantial, often dominating percentage of the resources committed to the entire litigation process; (2) discovery tools are likely to be used more extensively and intensively; (3) tactical considerations are more likely to affect decisions about discovery, and tactical 
maneuvering is likely to play a substantially larger role in the discovery process; ${ }^{19}$ (4) discovery is less likely to be successful in the sense that the parties' discovery efforts often fail to dislodge all the significant information from their opponents; ${ }^{20}(5)$ the attorney-client privilege, the workproduct doctrine, and other doctrinal sources of protection of information are likely to be invoked more frequently and their invocation is more likely to provoke costly disputes; ${ }^{21}(6)$ clients are more likely to play an active role in making decisions about discovery matters and more likely to exert pressure on counsel both to resist complying with some discovery requests and to use discovery tools to retaliate against or harass opposing parties. ${ }^{22}$

\section{A. Dimensions of Inefficiency}

The principal features which the interviewed attorneys ascribed to discovery in the subworld of the larger cases can be synthesized into one dominating characteristic: inefficiency. That inefficiency has several major components, one of the most pronounced of which is wastefulness. Many larger case litigators complained that much of the information requested by opposing parties is either wholly irrelevant to matters in dispute or of only marginal utility ${ }^{23}$ and, correspondingly, that only a small percentage of the information their own discovery efforts produce is really useful. ${ }^{24}$ Larger case attorneys also observed that to uncover gen-

19. Several questions were designed to yield information about the role of tactics in discovery. When respondents were asked to estimate the percentage of their civil cases during the preceding five years in which their use of discovery tools had been affected by at least one tactical purpose, the mean percentage provided by 39 larger case attorneys was 93 ; that provided by 36 smaller case attorneys was 71 . See also note 8 supra.

20. One question, e.g., asked attorneys to estimate the percentage of the cases they had settled during the preceding five years in which they believed that they (or their clients) "still had arguably significant information (including information protected by privilege) which . . . another party had not discovered." The mean of the percentages provided by 39 large case lawyers in response to this question was 56; the comparable mean provided by 37 smaller case attorneys was 26 . See also note 11 supra.

21. See, e.g., note 10 supra. One attorney opined that large corporate parties attempt to use the attorney-client privilege extensively to protect sensitive information from disclosure and such efforts often are successful because the scope of the privilege with respect to corporations is unclear. Some corporations routinely circulate internal memoranda through corporate counsel's office in order to be able to invoke the privilege to protect such memoranda if their production is requested in future litigation.

22. E.g., attorneys who indicated that on one or more occasion a client had "attempted to influence or pressure [them] not to produce information sought through discovery" were asked to estimate the percentage of their cases during the preceding five years in which that had happened. The mean of the percentages provided by 29 larger case attorneys was 32; the mean provided by 32 smaller case attorneys, 13.

23. One attorney described a common discovery sequence as consisting of an overbroad request followed by overbroad objections and overinclusive assertions of privilege. See also note 12 supra.

24. One said it is like "going for a pig in a poke in 90 percent of discovery." Less colorfully, another opined that "in 60 percent of discovery efforts the results do not justify the cost of acquisition." Negative efficiency sentiments were expressed about virtually every major discovery tool. Many attorneys said that answers to interrogatories often are virtually useless because they are 
uinely important information often requires considerable tenacity, multiple discovery probes employing several different kinds of discovery tools, skill in framing and sequencing questions, ${ }^{25}$ foresight and good fortune in timing discovery events, patience in sifting through the immense amounts of material produced in the discovery process in big case litigation, and the discipline and money to mount systematic follow-up efforts near the close of the pretrial period.

That litigators are required to develop such skills and professional habits suggests other dimensions of the inefficiency that discovery tends to display in the larger cases. As in smaller case litigation, delay is a significant problem. Many larger case lawyers appear routinely to overcommit themselves and to feel relatively little pressure to comply punctually with individual discovery requests. They regularly request extensions of compliance deadlines, and lawyers conducting discovery are often forced to exert pressure (through motions to compel or threats thereof) on opposing attorneys and parties to induce them to respond even to routine demands for information. ${ }^{26}$ One exception to this generalization is noteworthy. Some litigators reported that a few judges in the federal district court for the northern district of Illinois use regularly scheduled status conferences to systematically impose pressures on counsel and parties to conduct discovery expeditiously and to respond promptly to requests for information from other parties.

One important difference between smaller and larger case litigation may be that in the latter the problem of delay appears to be more often a product of intentional tactical jockeying than it is in the smaller cases. In one lawyer's words, the "sophisticated clients know what the discovery system is all about and they know that discovery is a business. In big cases the goal is to delay the resolution. They make a decision about how

prepared by attorneys (not clients) whose goals are to obfuscate and to provide as little important information as possible.

Several lawyers also decried the alleged waste involved in taking depositions. Estimating that "less than 10 percent of all deposition pages" ever are admitted into evidence, one litigator insisted (perhaps with more symmetry than logic) that " 90 percent" of the time committed by counsel to this form of discovery is wasted. Many respondents also complained about overproduction in response to requests for documents. One litigator offered a graphic example: "We have a case where over a million documents have been produced. I would guess less than 10 percent are relevant; less than that are admissible; and the very important information will be lost because [the documents containing it] are buried." These comments cannot be taken quite at face value. Much of the effort in investigation, research, and discovery is bound to lead to dead ends. That is the nature of the process of obtaining and marshaling facts.

25. See, e.g., note 9 supra.

26. Respondents were asked to estimate the percentage of their cases during the preceding five years in which "extended delays in responding to [their] discovery requests" had made their discovery more difficult or accounted for them not discovering or pursuing some information. The mean of the percentages provided by the 42 larger case litigators in response to this question was 52 percent. 
long they can delay and hold on to the money." Echoing this view, another litigator declared: "Discovery is a business. How long can I pay these attorneys to avoid the outcome of the case becomes the businessman's question today." More colorfully, another respondent admitted that as a defense attorney he "just loves delay" and that he "drags these babies out forever."

Quantifiable data produced by the interviews support the impression created by these statements. For example, the attorneys in the sample group were asked to estimate the percentage (if any) of their cases during the preceding five years in which the purpose of gaining time or slowing down an action had been a factor affecting their use of discovery. While the mean of the percentages provided by lawyers who devoted 50 percent or more of their time to work for individuals was 26 percent, that same mean for litigators who devoted 50 percent or more of their time to work for corporate clients was 46 percent. Among the several factors which account for this difference are: (1) larger cases tend to involve greater amounts of data, thus creating greater needs for time in responding to discovery, (2) the stakes are higher in larger case litigation and more money can be saved by postponing settlement of an obligation, and (3) a greater percentage of the smaller cases than of the larger matters are filed in the state courts in Cook County, where the five-year civil trial backlog (as compared to about a two-year wait in the federal courts for the northern district of Illinois) creates delays of sufficient length to obviate much need for tactical maneuvering to postpone the day of judgment.

In larger case litigation pretrial information exchange also appears to be accompanied by considerably more interparty and intercounsel friction than in the smaller cases. Attorneys whose practices revolve primarily around larger cases more often complain than do their smaller case counterparts about harassment, ${ }^{27}$ overdiscovery ${ }^{28}$ (quaintly characterized by some as discovery by "avalanche"), overproduction (referred to variously as the "warehouse" tactic or the "Hiroshima" defense), and

27. See, e.g., note 12 supra. One attorney declared that "everything in discovery is a war of attrition" and that it is more often the cost of that warfare than the merits of particular disputes that dictates the terms of settlements. Another attorney complained that opponents often "try to spend you into oblivion-[to] blow you out of the water if you and your client don't have resources." An example of a more subtle form of harassment was provided by a lawyer who observed that "a nice way to tie up the other side" is to secure a protective order which limits the number of people within the structure of a corporate client with whom opposing counsel can share information and discuss the case. Such orders, according to this respondent, can impair an attorney's capacity to prepare for trial and can force him to spend time and money trying to justify a modification.

28. See note 27. One litigator suggested that overdiscovery by plaintiffs can have the effect of discouraging settlement. According to this theory, when plaintiffs overdiscover a case they force defense counsel to invest substantial time and money in responding to requests for information and, thereby, often push the defendant's costs in the litigation past the point where defense counsel might be interested in or could justify settling the matter. 
other efforts to distract opponent's attention from important information. ${ }^{29}$

Evasive or incomplete responses to discovery requests also are a persistent and serious source of frustration and difficulty in larger cases. ${ }^{30}$

The desire to avoid disclosure can affect the way litigators help their clients prepare for responding to many different kinds of discovery probes. Some lawyers, for example, carefully avoid doing anything to refresh a client's recollection before a deposition-hoping that faded memories will result in opponents acquiring little of value. One attorney admitted that he "schools" his deponents to answer in the subjunctive and to be as evasive as possible in order to decrease the possibility of their being impeached through their deposition testimony.

The game of evasion reportedly is played most studiously, however, in "answering" interrogatories. One lawyer expressed what appears to be a widely shared belief when he declared that "any good attorney can shadowbox an interrogatory." Another, noting that "the name of the game" is evasion and incompleteness, reported a federal judge as saying that "interrogatories are useless because any lawyer who can't answer interrogatories without giving [an] opponent useful information is not worth his salt."

The wastefulness, delay, and friction which reportedly attend the discovery process in large case litigation increase its cost and, thereby, add to another dimension of the system's overall inefficiency. Perhaps surprisingly, large case lawyers and attorneys whose dominant client types are corporations complained more often about the cost of discovery than did smaller case lawyers and counsel whose dominant client types are individuals. ${ }^{31}$ Even litigators who frankly admitted that they were

29. When asked whether "the purpose of distracting another party's attention from or obscuring the existence of information ever affected the way [they had] shaped their responses to another party's discovery," smaller case attorneys responded in the affirmative almost as often ( 85 percent) as did larger case lawyers (88 percent). There was a striking contrast, however, between the two kinds of lawyers with respect to the reported frequency with which the purpose of distracting an opponent had affected responses to discovery. Attorneys who indicated that their responses to discovery had been affected by this purpose at least once were asked to estimate the percentage of their cases in which this had occurred. While the mean of the responses to this question by larger case lawyers was 50 percent, the comparable mean for smaller case attorneys was 27 percent.

30. See note 9 supra. One respondent generally characterized his goals in discovery as "trying to get as much information as possible from [each] opponent while giving up as little as possible." In a similar vein another attorney declared that "the purpose of responses to discovery is to give as little as possible so [your opponents] will have to come back and back and maybe will go away or give up."

31. Among the smaller case lawyers interviewed, 41 percent volunteered that cost was a problem in the discovery system; the comparable figure for larger case attorneys was 55 percent. Among lawyers for whom corporations were the source of 50 percent or more of their work, 70 percent voluntarily identified cost as a problem in discovery; the comparable figure for attorneys for whom individuals provided 50 percent or more of their work was 38 percent. 
becoming wealthy primarily because of fees attributable to discovery expressed amazement and concern about the rapid escalation of the expense of conducting and complying with discovery.

There appeared to be a virtual consensus among larger case lawyers that the discovery system as they experienced it would not fare well in a rigorous cost-benefit analysis: many such lawyers apparently believe that the expense the process generates is often disproportionate to the value of the information it yields. A few lawyers expressed the fear that skyrocketing costs might provoke major institutional clients to impose significant restrictions on the ways their attorneys conduct litigation, to search much more intensively for means of resolving disputes other than litigation, or to insist on major, structural changes in the current system of adjudication. While data produced by the pilot project do not indicate how widespread such fears are or whether feelings among clients are sufficiently intense to justify such concerns, it is clear that many lawyers perceive the rising costs of discovery as a serious problem.

One other important aspect of the inefficiency of discovery in large case litigation remains: the shortcomings of the process as a system for information distribution. The data generated by the interviews of Chicago lawyers indicate that there are dramatic differences between smaller, simpler cases and larger, more complex litigation in how well discovery achieves the goal of distributing the relevant information relatively evenly among the parties. ${ }^{32}$ In smaller, less complicated litigation the data suggest that roughly 25 percent of the lawsuits are terminated (by settlement or trial) with at least one party believing it knows something of significance about the case that other parties have not discovered. ${ }^{33}$ By contrast, the data indicate that more than 50 percent of the larger, more complex matters are closed with at least one party believing it knows something of significance that opposing parties do not know. ${ }^{34}$ These figures, considered against the backdrop of the assessments reported above, provoke an obvious question: is the system of discovery functioning acceptably if, with considerable inefficiency and at great cost, it distributes information among the parties fairly evenly in less than half of the larger cases in which it is used?

A summary comparison of the observations about discovery made by smaller case lawyers with those made by larger case attorneys creates the impression that the discovery system works best when it is used least and

32. In Hickman v. Taylor, 329 U.S. 495, 507 (1947), the United States Supreme Court declared that "[m]utual knowledge of all the relevant facts gathered by both parties is essential to proper litigation" and indicated that discovery is the principal mechanism by which that goal is to be achieved.

33. See, e.g., notes 11, 13, and 20 supra.

34. Id. 
that the more the system is used (e.g., in larger cases), the less effectively it accomplishes the objectives for which it was designed. In general, attorneys who use discovery tools intensively tend to be far less happy with the system than are attorneys who use it less. This impression provokes the question: do we have a good discovery system if only those who use it least are relatively satisfied with it?

\section{B. Thoughts About Causes}

Attorneys in the sample group identified several factors and phenomena as contributing to the limitations of the discovery system in larger case litigation. One factor that obviously helps account for differences in the effectiveness of discovery between simpler and more complex cases is the sheer volume of information which must be processed in complex litigation (especially in antitrust, trade regulation, unfair commercial competition, and securities matters). As the volume of potentially relevant information increases, the likelihood that an opponent will discover all the significant data decreases. Similarly, increases in the amount of information that must be exchanged increase the number of opportunities for disagreement, delay, tactical maneuvering, error, and oversight. ${ }^{35}$

\section{Contributions by Counsel}

None of our respondents, however, argued that expanded volume of information by itself accounted for all the differences between large and small case discovery. Some suggested, moreover, that the amount of information the discovery apparatus is forced to process in any given complex suit is rarely fixed by inherent requirements of proof but often is determined instead by characteristics of the lawyering in the matter.

Meter running (performing unnecessary work primarily for the purpose of milking additional fees from clients) is reported to be a common abuse. ${ }^{36}$ Further, there are various costly forms of harassment which can expand the volume of information in given lawsuits. Among these, the

35. According to many of our respondents, failures by lawyers to pursue relevant information with sufficient tenacity and skill often account for the shortcomings of the discovery system. The author will explore the roles played by such failures and will suggest some explanations for these perceptions in a subsequent essay.

36. None of our respondents admitted to "meter running," though many insisted that such practices were widespread among other lawyers. Several lawyers who complained about "meter running" primarily represented plaintiffs against insurance companies. They accused some counsel for carriers of more than occasionally refusing a reasonable settlement demand early in the pretrial period solely to run up sizable fees by conducting and responding to discovery. In support of this accusation, at least one plaintiff's lawyer contended that attorneys for carriers often settle cases just before trial for approximately the same amount that had been demanded before costly discovery was undertaken.

Another respondent opined that larger firms are guilty of meter running because "they have young lawyers, paralegals, and researchers who they must keep busy and bill time for." 
most obvious is overproduction of documents in response to discovery requests. Another is identifying, in answers to interrogatories, dozens of people who "have relevant information" when only one or two know anything of real significance. Still another is seeking more information through discovery than needed to have "something to compromise with" if the opponent objects. Yet another is coaching deponents to wander off on harmless, tangential subjects to distract opponents and consume time.

Another reported use of discovery that can expand the volume of information produced in one lawsuit beyond its proof requirements is conducting discovery in certain subject areas or from certain nonparties not to acquire relevant evidence but to pressure an opponent to settle. Respondents offered several examples: demanding that an opponent produce his income tax returns to capitalize on fears that disclosure of income could lead to difficulties with the government or a spouse, exploring politically sensitive subjects in suits against public agencies or officials to capitalize on fears of political repercussions, inquiring into the dating habits of a separated spouse or threatening to depose the third member of a relationship whose triangularity would best be kept secret, and focusing discovery probes on arguably illegal and clearly embarrassing corporate "contributions" to foreign governments or officials.

Another tactical abuse that can expand substantially the volume of information is using discovery in one lawsuit to serve purposes beyond the pending litigation or to satisfy needs generated in other proceedings. For example, discovery in pending litigation reportedly is used sometimes to set up a lawsuit against an unsuspecting or not completely defended third party (e.g., by seeking documents from or deposing the officers of a nonparty). Another example was provided by an attorney who bragged that when the rules of an arbitration prevented him from acquiring information from an opponent he filed a civil action and used discovery in it to circumvent the arbitration's limits.

In addition, attorneys in the sample group pointed out several ways in which bad lawyering can needlessly increase the volume of information exchanged during discovery and, thereby, decrease the efficiency and increase the cost of the system. One is failure to develop early in litigation clear theories of liability or defense to guide discovery efforts. Thus, some lawyers think overdiscovery often is attributable to the fact that conducting discovery is "easier than thinking," i.e., easier than creating a coherent, tight theory which integrates evidence with law to produce a premise for liability or a justification for challenged conduct.

Studies recently conducted under the sponsorship of the Federal Judicial Center, however, suggest that the perception that opposing counsel is overdiscovering a case or does not have a coherent theory to 
guide his discovery may be caused in some cases by the responding attorney's failure to understand the theories the discovering attorney is pursuing, e.g., when the discovering attorney is trying to develop an unusual or innovative basis for liability. These studies, conducted by Joseph L. Ebersole and Barlow Burke, are scheduled for publication during 1980 by the Federal Judicial Center in a soft-cover report entitled Discovery Problems in Civil Cases.

Chicago litigators offered additional explanations for overdiscovery. Some pointed out that it often was necessary to shape initial discovery requests broadly in order to acquire sufficient information about an opponent's procedures (or structure or history) to frame, in subsequent rounds of discovery, the precise, penetrating questions on whose answers the case might turn. One plaintiff's antitrust lawyer complained that "his biggest problem with discovery" was caused by the fact that he often did not "know enough before taking discovery to focus his probes . . . and [to] avoid getting huge document responses which are so time consuming to go through."

The same lawyer noted that another factor works in tandem with "insufficient information" to encourage attorneys to pose broad discovery requests, especially during the early stages of preparation. That second factor is fear of opposing counsel's evasiveness. According to this attorney, narrowing the scope of requests increases the risk that an opponent will be able to avoid producing all the information that could inculpate his client. Prematurely narrow discovery probes, in other words, are likely to miss some helpful data.

Another possible explanation for overdiscovery was suggested by a respondent who pointed out that lawyers sometimes intentionally repeat the same questions during a single deposition, or in different depositions, or in different discovery devices (e.g., interrogatories and depositions) to test the reliability of responses or in the hope that the different responses will produce exploitable inconsistencies.

Another problem resulting in unnecessary information is inability to predict the kinds of information likely to exist in given types of litigation. Still another, perhaps more culpable, cause is failure to study or to understand information that is available from one's own client or that has been produced by others and, therefore, needlessly repeating discovery probes. ${ }^{37}$

37. One respondent complained, e.g., that "attorneys spend lots of time discovering information that is already known-mostly because of attorneys' bad habits, e.g., depositions are regularly too long." But "attorneys' bad habits" are not the only causes of this form of overdiscovery. Other lawyers suggested that it could be caused by the fear of being sued for malpractice (see infra at 244) or the need to formalize (e.g., for evidentiary purposes) confirmation of certain information. 
Poor case and office management practices, most notable in case overloads and overcommitted schedules, and inflexibility in approaches to discovery in different kinds of cases also add to the problems of overdiscovery.

The last mentioned phenomenon warrants elaboration. An apt characterization of this inflexibility emerged from the interviews: "inertia of style." As this phrase suggests, the problem consists of litigators developing patterned modes of conducting and responding to discovery, modes which lawyers tend to follow fairly rigidly in most of their litigation, regardless of special or unusual features of given lawsuits and, therefore, of the appropriateness of their established patterns. Some attorneys indicated that through an only partially self-conscious process they had built into their discovery "pattern" not only set sequences in which they would employ different discovery tools and pursue different kinds of information but also certain tactical maneuvers. Some lawyers also admitted that this process of "patterning" had proceeded so far that they no longer conceived of some routine practices as "tactical" at all, even though when the lawyers had developed the practices early in their careers they had employed them very self-consciously and for specific tactical purposes.

While at least some lawyers in virtually every subcategory of civil litigation seem to develop patterned modes of discovery behavior, the content, scope, and rigidity of these habits apparently vary considerably between different lawyers, firms, and types of practice. Observations by several attorneys suggest, however, that the "inertia of style" phenomenon tends to be most visible and most troublesome among big case lawyers in big firms. The phenomenon was reported as especially prevalent in large firm practice not only by smaller case lawyers from smaller firms, who observed it on the relatively rare occasions when they were involved in litigation in which large firms participated, but also by large case lawyers, who described the forms it manifested within their own firms and admitted to being victimized by it themselves. These lawyers identified several factors which they believe help account for the prevalence of the "inertia of style" problem in large firm practice. One important source of pressure to form relatively rigid and comprehensive approaches to discovery in larger case litigation appears to be the size and complexity of the matters which counsel routinely must struggle to master. Large cases tend to involve substantial sums of money, subtle legal theories, the need to organize, digest, and control huge amounts of information, and confrontations with opponents who have considerable resources and strong incentives to commit those resources to seeking advantages in the discovery 
arena. These characteristics of larger cases virtually compel the attorneys who regularly litigate complex matters to develop "systems" for processing lawsuits-systems whose primary purpose is to leave as little to chance as possible. Once developed, such systems take on a life of their own. ${ }^{38}$ Some big case lawyers attributed that "life" to the reassurance such a system can provide its user. According to this theory, counsel can become psychologically dependent on his system when he uses it to help ward off the anxieties that attend big case litigation and to reduce the number of decisions he otherwise would have to make afresh in each case.

One attorney went so far as to characterize discovery as a "crutch for litigators who are afraid to try cases." And according to another lawyer big case litigators who devote huge percentages of their professional time to discovery develop great expertise in discovery techniques but lose or never develop skills as trial counsel. When such attorneys become responsible for training younger litigators, the only expertise they can teach is in methods of discovery. It follows that the training they offer perpetuates and, perhaps, intensifies the dominance of discovery in big case litigation.

Some large firm lawyers suggested an additional and closely related psychological theory to help account for the inertia of style phenomenon in big case litigation. This hypothesis holds that large law firms employ a disproportionate percentage of lawyers with "perfectionist-compulsive" personalities. The attorneys who advanced this theory believe that people with "perfectionist-compulsive" tendencies often perform very well in law school (and thus can qualify academically for jobs with large firms) and are likely to be attracted by the challenges and rewards (intrinsic and extrinsic, e.g., prestige) of big case litigation. Because litigators with these psychological characteristics are especially anxious about making errors of omission, so the theory goes, they are particularly prone to develop elaborate systematic procedures for attacking all litigation problems.

The pressure to systematize that the nature of the litigation and the personality types of the lawyers generate reportedly is reinforced by the hierarchial distribution of power in large firms and, to a lesser extent, by fear of sophisticated and sometimes aggressive institutional clients. Professional habits tend to be formed early in careers. When a young, inexperienced lawyer with a perfectionist personality type begins confronting the demands of complex litigation she does not do so in private. Instead,

38. One attorney observed that "the larger the cases, the more discovery is essentially selfgenerating. Big cases are routinely overdiscovered-so you end up with mounds of documents and, especially, pages of deposition transcripts that are useless and irrelevant." 
her work is subject to critical review and second-guessing both by supervising attorneys (who determine which young lawyers become partners) and by representatives of clients who may have had considerably more litigation experience than the young lawyer assigned to do the spadework in their case. The young perfectionist who wants to please her superiors and who is fearful of adverse judgments, especially because of errors of omission, is likely to feel considerable pressure to attack every assignment with a relentless, systematic thoroughness. Unfortunately, not every assignment calls for that kind of attack. Indeed, inertia of style is most visible as a phenomenon and appears to provoke most complaints when young attorneys from large firms bring the full panoply of their big case "system" to the smaller cases they occasionally litigate. Some predominantly smaller case attorneys complained that discovery in cases involving a big case lawyer too often becomes a painfully wasteful and expensive exercise in overkill. They reported, for example, that when a young, big firm attorney ventures into the relatively uncharted waters of tort litigation, she too often brings with her an insensitivity to cost and an inability to leave even the most remote stone unturned.

The inertia of style problem is related to another reported phenomenon that offers insights into ways lawyering patterns can affect the efficiency of the discovery system. This second phenomenon revolves around the concept of "regulars." As used by interviewed attorneys, the term "regulars" refers to groups of lawyers (1) who are experienced and regularly practice in a few closely related substantive areas of civil litigation, ${ }^{39}$ e.g., antitrust and trade regulation matters; (2) who practice for the most part in the same city or limited geographic area; (3) whose work is likely to bring them into contact with one another more than occasionally; (4) who know one another or at least one another's firms; and (5) whose practice "styles" are either similar or well known and essentially accepted by one another.

The regulars in any given area see themselves as forming a loose, informal fraternity of specialist peers. They believe that when fellow regulars are involved in a case the discovery system tends to function more smoothly, effectively, and efficiently than when nonregulars are involved..$^{40}$ Many lawyers reported, for example, that when opposing counsel are regulars, discovery is less likely to be burdened with tactical

39. Attorneys with general practices who only infrequently get involved with any kind of litigation reportedly are especially difficult to work with during discovery. One litigator complained that this class of lawyers, members of which appear with some frequency in suits filed in state court, simply "don't understand the spirit of the rules."

40. One respondent declared, e.g., that whether protective orders "work" (to overcome resistance to disclosure) depends on whether the opposing attorneys respect one another. 
jockeying, harassment, evasion, and other forms of resistance to disclosure than when the attorneys for the other parties are inexperienced or unfamiliar with the established practitioners in the field. Lawyers also reported that discovery among regulars is more likely to proceed informally (e.g., by letter) and through voluntary exchanges of information (even, on occasion, entire files) ${ }^{4}$ than is discovery when one or more of the parties is represented by counsel from outside the regulars group. Such informal and voluntary exchanges reportedly not only improve the psychological quality of litigators' lives but also reduce discovery costs for clients. While no lawyers claimed that the presence of regulars always reduces discovery difficulties, observations by many attorneys suggest that the difference between discovery with regulars and with nonregulars is substantial often enough to make the phenomenon significant. It also is worth noting that the regulars phenomenon was by no means confined to elite, sophisticated professional circles. It was reported, for example, by high volume personal injury and divorce lawyers as well as by specialists in antitrust and securities matters.

Conversations with attorneys who described the regulars phenomenon yielded several suggestions which might help explain it. One suggestion was that attorneys whose work brings them repeatedly into contact with one another form a community in which social and professional pressures can operate to restrain and in some measure to shape the behavior of individual lawyers in much the same way such pressures might operate in a small town. ${ }^{42}$ According to this theory, regulars assume they will have to

41. One insurance defense lawyer reported that in the great majority of his litigation opposing counsel work for the same specialist law firm and that the two firms have developed a "reciprocal" approach to discovery. Under this system of reciprocity, he said, "we open our files to each other so we don't battle over discovery."

42. Some attorneys from rural areas or small towns (not in the sample group for the Chicago project) have suggested to the author that discovery practice in such environments may tend to be substantially freer of tactical maneuvering and adversarial friction than it is in densely populated metropolitan areas. These attorneys have suggested that social pressures, which may operate with considerable force when the few lawyers in an area must deal with one another professionally and socially on a regular basis, may help account for what they perceive as a less intense, more straightforward style of litigation than they associate with practice in large cities. Recently completed (and not yet published) studies of differences between rural and urban lawyering by Professor Donald Landon of Southwest Missouri State College appear to offer support for these generalizations. Landon has concluded that in rural settings social pressures impose greater restraints on adversarial intensity between attorneys than do similar kinds of pressures in urban settings. He also raises questions about whether the social pressures which appear to restrain lawyers in rural settings result in less thoroughly professional and aggressive representation of clients than in urban areas. Landon has described aspects of his research and findings in two papers, the first of which he delivered in June 1979 in Knoxville, Tennessee, at the National Symposium on Rural Justice. That paper, "The Rural Lawyer: Characteristics, Clients and Practice," will be published with the Proceedings of the Symposium in the late summer of 1980. Landon delivered his second paper, "Lawyers and Localities: Community Influence and Legal Practice," in Milwaukee at the April 1980 meeting of the Midwest Sociological Association, which has no plans to publish the proceedings of this meeting. See also Prof.: Rural, Urban Law Practices Differ, B. Leader, Sept.-Oct. 1979, at 11. 
work with or oppose other regulars in future litigation. They also assume they will continue to meet other regulars with some frequency in professional organizations and in social settings. These assumptions tend to temper and civilize the way counsel treat one another-in part for purely social reasons and in part because future contacts would offer opposing counsel opportunities to retaliate for any perceived mistreatment by a fellow lawyer. Constraints based on such thoughts may be felt with particular acuity among groups of regulars whose capacity for retaliation is especially visible because they have substantial resources to commit to litigation (e.g., lawyers for large firms or for the government).

Another factor which some attorneys suggested might help account for the regulars phenomenon is the self-confidence they associate with experience and knowledge. According to this view lawyers with considerable experience in discovery and with thorough knowledge of the substantive law involved in their litigation trust their judgments and predictions far more than do their inexperienced counterparts. Such attorneys believe they readily can distinguish the significant from the trivial. They also believe they know what to expect and what not to expect from their opponents-procedurally, tactically, and in terms of the kinds of information that is likely to be produced. Confidence in their own perceptions and judgments, so the theory goes, makes these lawyers less professionally insecure than nonregulars and, therefore, less brittle, suspicious, defensive, and compulsive. The nonregulars' insecurity reportedly leaves them more likely to resist making disclosures which the regulars would consider routine. That insecurity also makes the nonregulars (so the regulars claim) more inclined to commit discovery overkill, less inclined to enter stipulations and to negotiate settlements, less inclined to proceed informally and to share information voluntarily, more likely to develop unreasonable expectations about the kinds of information opposing parties can produce, and more inclined to see in their opponents' conduct conspiratorial or underhanded designs to create and capitalize on unfair advantages.

Professional "class" antagonisms may reinforce these reported characteristics of nonregulars. Some lawyers from large firms suggested that attorneys from less prestigious practices occasionally enter litigation against big firm attorneys with quasi-political prejudices and a professional distrust that significantly complicates the discovery process. A few of our respondents unwittingly offered evidence to support such theories by openly displaying hostility toward big firm lawyers as a class. One smaller case attorney, for example, declared his dislike for and distrust of the "silkstocking boys" and admitted his desire to "show them something" when 
he litigated against them. Other lawyers suggested that such animosities might be provoked, at least in part, by the arrogance or condescension large firm lawyers sometimes display toward attorneys from less prestigious offices. Whatever the explanation, it appears that the presence of "regulars" and the absence of "class-based" professional animosities tend to have a salutary, lubricating effect on the discovery process.

Some interviewed attorneys identified an additional phenomenon of lawyering as contributing more than occasionally to problems with discovery. With no prompting by the interviewers, several lawyers volunteered critical assessments of the role played by house counsel ${ }^{43}$ in the discovery process. ${ }^{44}$ Lawyers offering these assessments opined that house counsel are more likely than attorneys employed in independent law firms to resist disclosure of information potentially damaging to their employer-clients, ${ }^{45}$ to use discovery tools or responses to discovery requests to harass or burden opponents, and to adopt a generally more guarded and suspicious posture toward relations with opposing counsel and parties. In short, house counsel reportedly are more likely to create friction and to obstruct the discovery process than are independently employed attorneys.

Lawyers who so characterized house counsel suggested several factors which might help explain the behavior they criticized. House counsel, they thought, are more prone than independent lawyers to identify with their employer-clients, i.e., less able to separate their own egos and interests from their clients and less able to sustain the detachment some lawyers believe is essential to sound professional counseling. To the extent that they are more likely than independent lawyers to identify with their clients, house counsel also are said to be more likely to take personally the accusations which accompany litigation and more likely to

43. As used here, the phrase "house counsel" refers to an attorney who is a salaried, full-time employee of a business rather than of an independent law firm.

44. Most of these assessments were not offered by house counsel themselves (of whom there were very few in the sample group) but by lawyers who had observed the behavior of house counsel through working with or opposing them in litigation. Because our data do not enable us to determine the precise number of attorneys who volunteered critical comments about house counsel, we cannot begin to estimate the extent to which the views described in the text may be shared by other attorneys who have had exposure in litigation to house counsel. Nonetheless, we report these observations because they were made spontaneously and by a sufficient number of lawyers to seem noteworthy.

45. One lawyer reported that during the time he served as house counsel for an insurance company, the carrier pressured him to resist making disclosures or to refuse to produce information being sought through discovery in about one of every four cases he handled. The same lawyer also reported that after resigning his position with the carrier and moving into a practice in which he offered independent representation primarily to plaintiffs, he felt much less pressure from his clients to resist discovery requests. Other data produced by the pilot study (data to be presented in a subsequent article) indicate that corporate clients are more likely than individuals to exert pressure on their attorneys to resist disclosures sought through discovery. See also note 26 supra. 
view discovery probes as unjustifiable invasions of their own privacy. According to some lawyers in the sample group such personal reactions by house counsel sometimes have roots not only in psychological sloppiness (i.e., ego blurring with clients), but also in the facts that underlie the litigation. Not uncommonly, report some independent attorneys, house counsel react personally to discovery because it focuses on decisions or actions in which house counsel participated. In such situations the company lawyer may resist certain disclosures because he fears exposure and critical review of his own conduct or wants to cover his own errors. The larger fear of being fired may lurk not far beneath the surface of such specific concerns. Moreover, some house counsel reportedly fear that they will be blamed for any significant litigation loss, regardless of whether they were involved in the conduct or in decisions that provoked the lawsuit. The relatively free flow of information through the discovery process appears to be one of the principal victims of such fears.

Another factor which some lawyers identified as contributing to the overall inefficiency of the discovery process is the reported rise, during the past few years, in concern about being sued for malpractice (that concern has been accompanied and perhaps in part inspired by a rise in premiums for malpractice insurance). While there was no consensus that fear of malpractice actions has increased significantly, those who do perceive this possible phenomenon believe that it has several kinds of adverse effects on discovery. Some attorneys claimed, for example, that fear of malpractice tends to increase counsel's resistance to making disclosures in response to discovery probes and, thereby, to increase the cost of information distribution. Since big case lawyers reported feeling pressured by their clients to resist disclosure more often than did smaller case attorneys, ${ }^{46}$ it seems fair to speculate that fear of malpractice is most likely to have this kind of negative impact on discovery (increasing resistance to disclosure) in larger cases.

Attorneys in the sample group reported that another, perhaps more frequent, consequence of the fear of malpractice is overdiscovery. One litigator, for example, described discovery as a "bottomless pit" and insisted that "any lawyer who doesn't exhaust all avenues is subject to criticism by his clients." Fear of such criticism reportedly motivates some lawyers "to put on discovery shows" for their clients, i.e., to engage in elaborate and highly visible discovery exercises at least in part for the purpose of convincing clients that they are being vigorously and thoroughly represented. Fear of malpractice also reportedly encourages

46. See note 22 supra. 
more discovery than might be necessary by moving litigators to use discovery tools to confirm the existence of already well-known evidence. One lawyer declared, for example, that in the past he had felt comfortable relying on at least certain kinds of representations by opposing counsel, but that in recent years, because of concern about malpractice actions, he has changed his policy and now would never rely on representations by opponents. Instead, he feels constrained to confirm information he already knows by formally "discovering" it.

\section{The Untoward Role of the Judiciary}

As the preceding discussion shows, lawyers blame lawyers for many of the problems with discovery. There is another group of actors in the discovery arena, however, on whom the litigators in the sample group placed much of the responsibility for the failings of the discovery system. Perhaps the single most dramatic product of the project's interviews is the anger and disappointment attorneys expressed about the role played by the judiciary in the discovery stage of litigation. While negative sentiments about the ways courts respond to discovery disputes and supervise the discovery system were not universally shared, they were far too widespread ${ }^{47}$ and intensely felt to be summarily dismissed as the inevitable disgruntlement that derives from lawyers' dependency on the judiciary. The existence of such substantial disaffection, which was expressed about judges in both the federal and the state systems, ${ }^{48}$ strongly suggests that somewhere in the dynamic between court and counsel there is a serious problem for the discovery system.

The anger and disappointment about the judiciary which attorneys ventilated during the interviews had several different foci. One of the most obvious was the negative attitudes the courts reportedly display toward discovery disputes and toward attorneys who turn to the judiciary for help with discovery problems. A large number of attorneys reported that many judges respond to discovery conflicts with an air of undisguised condescension, impatience, or open hostility-implying that involvement in these kinds of disputes is either beneath their dignity or an

47. When asked in an open-ended question to identify problems in the discovery system, a higher percentage of respondents ( 71 percent) mentioned something negative about the role of the courts than about any other type of problem or source of difficulty.

48. Among the 76 lawyers who reported devoting four fifths or more of their time to matters filed in state courts, 57 percent voluntarily identified the courts as having some negative impact on discovery. By contrast, among the 62 attorneys in the sample group who reported devoting comparably large percentages of their time to matters filed in federal court, 79 percent voluntarily identified the courts as sources of problems in the discovery stage of litigation. It must be remembered, of course, that federal cases tend to be larger, which complicates the matter and makes a simple interpretation of this disparity impossible. 
unjustifiable intrusion on their time. Other attorneys reported that many judges appear to lack interest in discovery problems and are unwilling to take them seriously.

Another oft-voiced characterization of the courts' attitude toward discovery is "naive." The most frequently cited indication of that alleged naiveté is the reportedly common judicial response to discovery disputes in which the court simply admonishes opponents to "go work it out yourselves." Many lawyers perceived in that response a failure by the courts to understand that discovery is fundamentally adversarial and that discovery disputes often are very real, i.e., that they arise out of strongly held and antagonistic beliefs about the propriety of given discovery probes or tactics and that their resolution often is perceived by counsel and client as of considerable importance to the outcome of the lawsuit.

The generalization that emerges from the numerous vocal complaints about judicial attitudes is that to a great many attorneys judges appear to believe that discovery disputes simply do not belong in courtrooms. Many lawyers deeply resent that attitude.

The judiciary's lack of hospitality to discovery problems reportedly is accompanied too often by incompetence in solving them. The most vitriolic criticisms were directed toward magistrates in the federal courts. While a few attorneys reported satisfaction with the performances of these officials, a great many more lawyers vehemently complained that most of the magistrates are woefully underequipped in talent, time, and temperament to resolve the complex discovery disputes that are referred to them. Criticism of judicial incompetence in handling discovery problems, however, was by no means confined to magistrates. A large number of the lawyers in the sample group also felt that many judges in both the state and the federal systems do a poor job of resolving discovery disputes. Many attorneys complained that judges' rulings on discovery controversies often do not seem to constitute "decisions" at all. Instead, such rulings often appear to be little more than preprogrammed responses which reflect deeply ingrained biases. Some lawyers perceived such biases to be reflections of fundamental postures toward discovery. In this view some judges are said to favor a wide-open, essentially unrestrained process of exploration and, therefore, tend to resolve most discovery disputes in favor of the party seeking disclosure. Other judges, by contrast, appear hostile to broad discovery and, therefore, seem strongly inclined to rule against motions to compel. Some attorneys claimed that much more specific biases inform the discovery decisions of some judges: e.g., biases in favor of certain types of parties (like the federal government) or against certain types of actions (like civil rights actions). 
While judicial bias was perceived by some attorneys to be a significant problem, others complained more generally that judicial resolution of discovery disputes often appears simply irrational and arbitrary. Some attorneys ascribed this appearance of irrationality in large measure to the intense time pressure under which judges often make decisions about discovery controversies. One attorney reported, for example, that it is not unusual for judges in the state courts in Cook County to hear between 15 and 20 motions during a single 30-minute session. Several lawyers opined that such relentless docket pressure makes it virtually impossible for judges to take the time necessary to fully understand each case in which the court is called upon to resolve a disagreement about discovery. The problems created by these severe time constraints are perceived as especially troublesome when a lawsuit involves complex factual or legal questions but is not one of the few highly visible or engaging matters that attracts the special and more detailed attention of the judge. In some lawyers' eyes it happens far too often that the most obvious product of the combination of time pressure and litigation complexity is judicial ignorance. Discovery disputes, according to some of our respondents, often represent only the tips of complex litigation icebergs, the bulks of which often remain beyond judicial visibility and comprehension unless and until cases go to trial.

One important consequence of these perceptions of negative judicial attitudes and limited judicial resources is a feeling shared by many Chicago attorneys that the courts very often fail to deliver effective assistance in solving discovery problems. In response to the question, "Do you feel that you get adequate and efficient help from the courts in resolving discovery disputes and problems," 69 percent of the responding attorneys said "no." Among big case litigators ${ }^{49}$ the figure was a staggering 93 percent.

As important as the problems described above appear to many attorneys to be, even more concern was expressed about another characteristic of judicial conduct in the discovery system. A substantial percentage of the lawyers in the sample group expressed the strong belief that both federal and state court judges are far too lenient with attorneys and clients who abuse discovery tools or fail to respond in good faith to proper discovery requests. Many litigators complained that most courts are transparently reluctant to impose sanctions at all and that when sanctions are imposed they often are too mild to serve as significant deterrents to future abuses. Several lawyers reported, for example, that it is widely 
believed among trial counsel that courts rarely will sanction an attorney or client for an initial violation of the rules of discovery. In fact, some judges reportedly are known to require at least three failures to respond to the same clearly legitimate discovery request before they will consider seriously a motion for sanctions. Complaints also were voiced about the habit some courts have acquired of postponing decisions about whether to impose sanctions until after litigation has been completed. That habit, it was said, results all too often in the imposition of no sanctions at all. That result, in turn, was attributed not only to a waning of interest by court and counsel in pursuing sanctions after a suit is terminated, but also to peer pressure on attorneys not to press for punishment of fellow lawyers after disposition of litigation.

It is only against the backdrop of the kinds of complaints described above that the full significance of one of the pilot project's most dramatic quantitative results can be appreciated. When asked specifically whether they would favor or oppose more frequent use of sanctions for discovery abuse, fully 80 percent of the lawyers interviewed declared that they would favor increased use of the sanctioning power. That percentage was even higher ( 90 percent) among big case lawyers. ${ }^{50}$ A substantial majority (67 percent) of all the attorneys in the sample group also indicated that they would favor "greater judicial involvement in the discovery stage of litigation." The percentage of big case lawyers ${ }^{51}$ who favored a more activist pretrial role for the courts was even higher: 82 percent.

These figures, in conjunction with the complaints about the courts described above, evidence a view which appears to be widely shared among Chicago litigators. That view is that the net effect of the courts' (1) negative attitudes toward discovery problems, (2) limited resources to commit to helping resolve discovery disputes, and (3) reluctance to impose sanctions is to very substantially dilute the judiciary's capacity to exercise meaningful control over the discovery system. Moreover, an overwhelming percentage of the attorneys interviewed seem to believe that this inability of the judiciary to function as a significant restraining and guiding force in the discovery process is one of the biggest single factors contributing to the inefficiency and abuse of the system.

Interviewed attorneys suggested several ways in which the judicial behavior described above adversely affects the discovery process and encourages its abuse. Some lawyers reported, for example, that the hostility and impatience many judges display toward discovery controversies leads some attorneys to believe that they can take only a limited number of

50. Id.

51. Id. 
discovery problems to court without alienating the judge and risking adverse rulings in future appearances. As a result of this sense of limited access to the judiciary, some attorneys reportedly feel pressured, before seeking judicial intervention in a discovery dispute, to engage in crude efforts to predict the number and importance of additional discovery controversies that are likely to arise before a given case gets to trial. If several significant disputes seem likely, counsel will feel considerable pressure in the early stages of litigation to accede to even unreasonable positions taken by an opponent. Several attorneys expressed resentment and frustration over feeling pressured by the courts into such positions. The courts' dislike of discovery controversies and the restraints that dislike imposes on attorneys' recourse to the judiciary also reportedly encourage abuses of discovery by those lawyers who perceive that their opponents are inhibited from seeking aid from judges in response to transgressions.

The widely shared impression that if judicial intervention occurs at all it is likely to be superficial also reportedly encourages discovery abuse. If the details of counsel's conduct are not likely to be systematically scrutinized, and if a court's rulings on discovery motions appear as likely to be guided by general predispositions or biases as by thorough knowledge of given cases, lawyers are said to feel less constrained to conduct or respond to discovery in close conformance with the spirit of its rules. One attorney reported, for example, that some lawyers object to as many discovery questions as possible on the theory that when courts rule on motions to compel they will sustain some of the objections simply out of a desire to placate both sides. Thus, raising numerous objections is seen as increasing the likelihood that counsel will succeed in preventing the disclosure of some information.

The characteristic of judicial responses to discovery problems which was by far the most often cited as encouraging discovery abuse, however, is the courts' studied reluctance to impose sanctions. In fact, many litigators apparently would go a step further and suggest that the infrequency and the leniency with which courts use their sanctioning power is the root cause of discovery abuse. ${ }^{52}$ Such lawyers would argue that it is the relatively minimal risk of sanctions that sets cycles of abuse in motion. According to this theory the absence of a real threat of sanctions creates a restraint vacuum that sucks litigators into temptations too great

52. One attorney admitted that a major reason lawyers in his firm and elsewhere construe discovery probes as narrowly as possible, so as to justify responding with as little information as possible, is that "judges almost never sanction such efforts by counsel." Another attorney complained that even after three successive demands for the same information and filing a motion to compel, judges routinely would extend the time in which the opposing party could respond to his discovery. 
to resist. Attorneys who are under acute time constraints, or who are saddled with weak positions, or who are vulnerable to pressures from clients, and who believe there is little likelihood of being punished for a violation of the rules may not have the will to forgo an opportunity to attempt to gain an advantage through a violation. Lawyers also observed that the relative rarity of sanctions permits abuses to beget additional abuses. Several litigators described their own willingness to respond in kind after an opponent has attempted to abuse the tools of discovery. Some attorneys also reported being pressured by their clients to use discovery as a retaliatory weapon to harass or burden opponents who the clients believe have used discovery tools unfairly. Finally, it should be noted that the remoteness of restraint by the judiciary leaves considerable room not only for clear abuses but also for the extensive tactical jockeying which, at least in the larger cases, appears to contribute significantly to the inefficiency of the discovery process.

While accurate assessments of judicial attitudes and their impact on discovery cannot be based primarily on data from lawyers, the interviews conducted during the pilot study suggest that there may be substantial differences between litigators' and judges' expectations about the discovery system and their ideas about how that system should be managed. Most of the lawyers interviewed clearly see the discovery process as adversarial. ${ }^{53}$ Many attorneys, for example, declared that it is not part of their job to help an opponent uncover relevant information: they would make disclosures if opposing counsel structured discovery probes in a manner that left no alternative, but they would volunteer no assistance and they would provide nothing that was not clearly demanded. ${ }^{54}$ Even attorneys who expressed dislike for jockeying for informational advantages and a preference for more straightforward exchanges of data appear to indulge no expectation that such exchanges would become the norm under the current discovery system.

By contrast, many of the observations attorneys made about judicial responses to discovery disputes suggest that even judges who had sub-

53. The following comments by interviewed attorneys are among the most graphic testimonials to this attitude:

Our job is to win for our side. We aren't out to do justice; that's the judges' job.

Discovery is good for our business but has nothing to do with justice. Some do-gooder invented discovery and didn't do good with it. It's unfortunate for the poorer people and I don't like this, but it's a game we play and we make dollars at it.

Most attorneys still see discovery as a game and play it to the hilt to avoid disclosure.

The first wave of discovery is a mechanical process, but after that it's all tactics and strategy.

54. One respondent bluntly articulated his "philosophy" for responding to discovery as follows: "Never be candid and never helpful and make [your] opponent fight for everything." 
stantial litigation experience before moving to the bench may acquire a peculiarly judicial set of attitudes toward discovery, attitudes that are quite incompatible with a view of discovery as essentially adversarial. If there are uniquely judicial attitudes toward discovery they may help account for the perception by some litigators that some judges naively fail to understand the competitive nature of discovery. One clue to the character of judicial attitudes may be the impression many lawyers reported that judges seem to believe that discovery disputes simply have no proper place in court. That attitude, if accurately perceived, may reflect more than judicial frustration over inadequate resources to cope with demands; it also may reflect a view that regardless of how discovery has been practiced, it ought not be adversarial. Concern about inefficiency and unfairness in civil litigation may lead significant numbers of judges to conclude that maneuvering for informational advantage and resisting disclosure is fundamentally inconsistent with the spirit and objectives of the discovery apparatus. ${ }^{55}$ Thus, impatience with discovery disputes being brought into court may be rooted in judicial expectations that discovery should function as a private, self-executing system for sharing information-a system in which the courts should have to intervene only in exceptional circumstances. Such assumptions also may help account for some courts' unwillingness to expend substantial efforts calibrating the severity of individual transgressions of discovery rules.

Descriptions by interviewed lawyers of their own attitudes toward discovery and of their perception of the judiciary's reactions to discovery disputes suggests that many litigators and judges may have fundamentally different expectations of the system. If such differences exist, they may help account for the difficulty some judges and some litigators seem to have communicating about discovery problems. Since difficulties in communication and differences in expectations might contribute significantly to the shortcomings of the discovery system, any comprehensive effort to evaluate that system should include careful study of the roles, perceptions, and attitudes of the judiciary.

55. See, e.g., Charles B. Renfrew, Discovery Sanctions: A Judicial Perspective, 67 Calif. L. Rev. 264 (1979); William W. Schwarzer, Managing Civil Litigation: The Trial Judge's Role, 61 Judicature 400 (1978); Marvin E. Frankel, The Search for Truth: An Umpireal View, 123 U. Pa. L. Rev. 1031, 1054 (1975); Milton Pollack, Pretrial Procedures More Effectively Handled, 65 F.R.D. 475 (1974); William H. Becker, A Modern Efficient Use of the Bar and Other Parajudicial Personnel in Pretrial of Ordinary Civil Actions, 53 F.R.D. 159 (1971); Milton Pollack, Pretrial Conferences, S0 F.R.D. 449 (1970); see also B. Thomas McElroy, Federal Pre-trial Procedure in an Antitrust Suit, $31 \mathrm{Sw}$. L.J. 649, 683 (1977); S. Mark Werner, Survey of Discovery Sanctions, 1979 Ariz. St. L.J. 299 (1979). For a description of expectations about discovery among scholars and judges who helped shape the modern discovery rules see Wayne D. Brazil, The Adversary Character of Civil Discovery: A Critique and Proposals for Change, 31 Vand. L. Rev. 1295, 1299-1303 (1978). 
